\title{
REFLEXÕES SOBRE A DIVERSIDADE NA EDUCAÇÃO INFANTIL: UM OLHAR PARA A FORMAÇÃO DE PROFESSORES
}

\author{
REFLEXIONES SOBRE LA DIVERSIDAD EN LA EDUCACIÓN INFANTIL: UNA \\ MIRADA PARA LA FORMACIÓN DE PROFESORES
}

\author{
REFLECTIONS ON DIVERSITY IN CHILDREN EDUCATION: A LOOK AT \\ TEACHER TRAINING
}

Fernanda Delai Lucas ADURENS ${ }^{1}$

Patrícia Alzira PROSCENCIO ${ }^{2}$

Danielle da Silva Pinheiro WELLICHAN ${ }^{3}$

RESUMO: o presente estudo tem como objetivo propor reflexões sobre a diversidade na Educação Infantil, considerando especificamente o público-alvo da Educação Especial. Inicialmente abordou-se o percurso da Educação Infantil desde o período assistencialista até o seu papel educacional associando os aspectos do cuidar e do educar. Em seguida, tratou-se do conceito de diversidade e suas implicações na educação, bem como sua importância no princípio da Educação Básica. Por fim, discutiu-se a respeito da formação dos professores para que seja possível viabilizar uma educação de qualidade para todos, com foco na valorização da diversidade. Concluiu-se que há número reduzido de pesquisas com a temática e que a formação de professores é um caminho fundamental para que se efetive a inclusão e se amplie o olhar, considerando a diversidade.

PALAVRAS-CHAVE: Diversidade. Educação infantil. Educação especial.

RESUMEN: El presente estudio tiene como objetivo proponer reflexiones sobre la diversidad en la Educación infantil, considerando específicamente el público objetivo de la Educación Especial. Inicialmente se abordó el recorrido de la Educación Infantil desde el período asistencialista hasta su papel educativo asociando los aspectos del cuidar y del educar. A continuación, se trató del concepto de diversidad y sus implicaciones en la educación, así como su importancia en el principio de la Educación Básica. Por último, se discutió sobre la formación de los profesores para que sea posible viabilizar una educación de calidad para todos, con foco en la valorización de la diversidad. Se concluyó que hay un número reducido de investigaciones con la temática y que la formación de profesores es un

\footnotetext{
${ }^{1}$ Universidade Estadual Paulista (UNESP), Marília - SP - Brasil. Mestranda em Educação na linha de pesquisa Educação Especial. Psicóloga, Especialista em Psicologia Clínica e de Saúde, em Intervenção Precoce em Clínica Interdisciplinar e Saúde Mental. ORCID: <https://orcid.org/0000-0002-4741-5532>. E-mail: fernandadla10@gmail.com

${ }^{2}$ Universidade Norte do Paraná (UNOPAR), Londrina - PR - Brasil. Docente e Especialista em Metodologia da Ação Docente, em Arte-Educação. Doutoranda em Educação, na linha de pesquisa Educação Especial UNESP/Marília. ORCID: <https://orcid.org/0000-0001-7504-0021>. E-mail: pproscencio@gmail.com

3 Universidade Estadual Paulista (UNESP), Marília - SP - Brasil. Doutoranda em Educação, na linha de pesquisa Educação Especial - UNESP/Marília. Bibliotecária e Pedagoga, Especialista em Educação Infantil, Especial e TGD. Mestra em Ciência da Informação. ORCID: <http://orcid.org/0000-0002-6978-7361>. E-mail: dany_unesp@yahoo.com.br
}

Doxa: Rev. Bras. Psico. e Educ., Araraquara, v. 20, n. 2, p. 150-163, jul./dez., 2018. 
camino fundamental para que se efectúe la inclusión y se amplíe la mirada, considerando la diversidad.

PALABRAS CLAVE: Diversidad. Educación infantil. Educación especial.

ABSTRACT: The present study aims to propose reflections on diversity in Early Childhood Education, specifically considering the target audience of Special Education. Initially the course of Early Childhood Education from the assistentialist period to its educational role was associated with aspects of caring and educating. Next, the concept of diversity and its implications in education, as well as its importance in the principle of Basic Education, was discussed. Finally, we discussed the training of teachers so that it is possible to provide quality education for all, with a focus on valuing diversity. It was concluded that there is a small number of researches on the subject and that teacher training is a fundamental way for inclusion to take effect and to broaden the view, considering diversity.

KEYWORDS: Diversity. Early Childhood education. Special education.

\section{Introdução}

Nos Parâmetros Curriculares Nacionais (PCNs) o multiculturalismo e a diversidade são assuntos necessários tanto para a escola quanto para a comunidade, pois tratam da pluralidade que envolve o indivíduo, gerados pela diversidade brasileira e que infelizmente, ainda prevalece cercada por estereótipos regionais, éticos, sociais e culturais. E para que a aceitação diante do diferente seja incorporada pelas crianças, os adultos pertencentes à instituição precisam demonstrar em seus cotidianos atitudes e ações que representem essa aceitação a fim de transmitir exemplos saudáveis para as crianças que ali convivem (BRASIL, 1998).

A diversidade se torna mais clara para as crianças quando se deparam com o diferente em seu cotidiano e justamente por isso, precisam ser orientados para desde cedo quanto a formação de se caráter.

De forma contínua e lúdica, os professores da Educação Infantil podem acompanhar as necessidades e as habilidades de seus pequenos explorando situações no contexto escolar de forma real e positiva, e nesse sentido, a diversidade se torna um assunto rico para ser explorado tendo em vista as ferramentas e recursos pedagógicos que essa fase escolar permite utilizar. Seja na cultura de um povo ou na natureza, buscar a singularidade baseada no respeito é trabalhar a diversidade como fator de enriquecimento pessoal e cultural, e se tratados desde as primeiras etapas escolares, a possibilidade de obter bons resultados é bem maior. 
Trabalhar toda essa diversidade na escola é contribuir com futuros cidadãos mais conscientes de seu papel na sociedade, contribuindo para o diálogo e o respeito ao diferente e é sob essa perspectiva que o texto a seguir se apresenta, associando os aspectos do cuidar e do educar no percurso histórico da Educação Infantil, discutindo a importância da formação de professores voltada as necessidades da diversidade na sociedade.

\section{Contextualizando a Educação Infantil}

Ao abandonar o campo meramente assistencialista, após percorrerem um longo caminho de lutas por direitos através de movimentos sociais (DIDONET, 2001; OLIVEIRA et al, 2011; KUPFER et al, 2016), a creche junto a pré-escola, tornaram-se um direito da criança e da família e dever do Estado (BRASIL, 1988) e passam a compor a Educação Infantil, primeira etapa da Educação Básica (BRASIL, 1996).

A Educação Infantil é a base do processo educativo, não somente pelo fato de compor o início da Educação Básica (VITTA, 2010; OLIVEIRA, 2013), mas principalmente por ser um período em que as crianças estão em pleno processo de desenvolvimento e constituição subjetiva (JERUSALINKY, 2002). Momento em que se constrói um alicerce para sustentar a estrutura que virá com decorrer dos anos.

Cada vez mais cedo os bebês têm ingressado nas creches em decorrência da transformação da dinâmica e configuração familiar, visto que a mulher, antes responsável primordial pelos cuidados dos filhos, conquistou um espaço no mercado de trabalho (CATALDI, 1992; ARAÚJO; GAMA; SILVA, 2013). Com isso, o bebê que anteriormente era cuidado apenas pela família, ingressa à escola, ampliando seu núcleo de convivência e articulando as duas instituições: família e escola, no cuidado e educação da pequena criança (OLIVEIRA, 2013).

Nesse sentido, torna-se fundamental uma interlocução entre as vivências do contexto familiar e as propostas pedagógicas oferecidas no espaço escolar, desenvolvendo aspectos da socialização, comunicação e autonomia (BRASIL, 2017). No entanto, a relação entre a família e a creche e a maneira como compartilham a educação das crianças é permeada por conflitos (MARANHÃO; SARTI, 2007, 2008; BAHIA; MOCIUTTI, 2017; ALJUSTREL, 2017).

Bichara (1992) apontou que há um conflito de emoções e sentimentos nessa relação entre família e creche no que diz respeito a cobranças e responsabilidades de ambos os lados. No contexto escolar, a participação da família restringe-se às reuniões bimestrais e 
convocações para discussão sobre o comportamento dos filhos. Na maioria das vezes não são envolvidas e inclusas em outras programações que ocorram na instituição com o verdadeiro intuito de aproximação entre escola e família (BAHIA; MOCIUTTI, 2017). Nem em situações em que se proponha atividades para que sejam realizadas entre pais/responsáveis e filhos e nem para a participação nos processos de tomada de decisões desse espaço, o que diverge de uma educação pautada na escola democrática. Nesse sentido, não há o compartilhamento da responsabilidade do processo educacional, envolvendo a escola, a família e a comunidade (BRASIL, 2004).

Um dos pontos de divergência entre a família e creche permeiam questões referentes às necessidades das crianças. Cada uma dessas instituições possui ora visões antagônicas, ora complementares acerca dessas necessidades. Essa dificuldade de diálogo e interlocução pode interferir no desenvolvimento da criança (MARANHÃO; SARTI, 2008). Outro ponto, abordado por Crespin (2016), com potencial para promover um desencontro de opiniões entre a família e a escola, está associado ao papel exercido pelas profissionais da creche. Elas cuidam de bebês, mas não são mães de cada um deles. A autora alertou a necessidade de um momento de escuta destinado a esse grupo de profissionais para que elaborem suas questões quanto ao exercício da função, com o intuito de dissociar o cuidado realizado na creche, que é de extrema importância, com os cuidados referentes a maternidade (CRESPIN, 2016).

Após a inserção da creche na Educação Básica, inicia-se uma discussão sobre o educar e o cuidar. $\mathrm{O}$ educar diz respeito à construção de conhecimentos para a compreensão de si, do outro e de seu entorno. O cuidar é atender as necessidades das crianças como o sono, alimentação, higiene, além da proteção, carinho e afeto envolvidos nessas e em outras atividades (KRAMER, 2005). Tal binarismo, cuidar e educar, deve ser superado, e ser considerados condições que se integram, já que são aspectos indissociáveis, essências para o desenvolvimento global dos pequenos alunos (MARIOTTO, 2003, 2009; SILVA; BOLSANELLO, 2002; NONO, 2015; ANDRÉ, 2016).

A forma como cuida-se e educa-se na Educação Infantil faz parte das práticas pedagógicas, contudo as ações desses profissionais devem ser mais abrangentes. Barbosa (2010), ressaltou que a prática pedagógica é abrangente no sentido de articular ações do professor, planejadas a partir de diversas concepções que vão além da educação como concepção de sociedade, de infância, envolvendo a aprendizagem e o desenvolvimento (BARBOSA, 2010). 
Nessa perspectiva, Oliveira (2013) afirmou que uma das principais funções da Educação Infantil é a formação para a cidadania. Essa construção se dá a partir da relação de respeito a diversidade, de sentimentos de benevolência em relação ao semelhante, de valorização do coletivo, o que implica agir de maneira ética e refletir sobre as próprias atitudes.

\section{Diversidade na Educação Infantil}

A diversidade é enfatizada nos documentos oficiais do Ministério da Educação sobre a Educação Infantil (BRASIL, 1998, 2006, 2010). Para Rendo e Venga (2006) a diversidade é a pluralidade de realidades, a valorização do diferente, promoção da interação social independentemente de cor, etnia, deficiência ou gênero. Nela está implicada a noção de igualdade, justiça e liberdade. Na educação, a diversidade trata-se de uma prática complexa que conta com o reposicionamento da sociedade, não somente uma mera readaptação (RENDO; VENGA, 2006). É uma prática que oferece protagonismo aos alunos e às suas diferenças, e propõe que convivam entre si sem qualquer tipo de discriminação, enriquecendo-os enquanto sujeitos (RENDO; VENGA, 2006).

Oliveira (2013) sinalizou que o olhar para a diversidade, para o respeito e a ética para com todos e principalmente ao que lhe é diferente se inicia nessa etapa inicial da Educação Básica e deve incluir nessa empreitada o direito da criança com Necessidades Educacionais Especiais de conviver e aprender junto aos outros. A criança não nasce preconceituosa, mas o seu entorno, o meio em que está inserida, pode contribuir tanto para que se desenvolva o preconceito e a discriminação ou o acolhimento e respeito.

No que diz respeito a criança, público-alvo da Educação Especial, a inclusão começa a ser discutida no âmbito da política educacional desde a promulgação da Lei No 4.024 de 1961, a 'Lei de Diretrizes e Bases da Educação Nacional' (LDBEN) que já tratava de questões relacionadas ao atendimento às pessoas excepcionais na Educação Básica. O atendimento especializado a pessoas com deficiência, transtornos globais do desenvolvimento e altas habilidades ou superdotação, preferencialmente na rede regular de ensino, passa a ser garantido na Constituição Federal como dever do Estado (BRASIL,1988) assim como previsto na LDB de 1996 (BRASIL, 1996). No entanto, mesmo respaldada pela legislação brasileira, ainda existem fragilidades no processo de inclusão que envolvem reformulações e ações no âmbito político, técnico-científico, pedagógico e administrativo (OLIVEIRA, 2006). 
Há uma carência de estudos que abordam a inclusão na Educação Infantil (MONTE, 2006; PEREIRA; MATSUKURA, 2013; OLIVEIRA, 2014), o que é preocupante, já que essa etapa da educação é fundamental para o desenvolvimento infantil, especialmente no caso de crianças com necessidades especiais (DE VITTA; EMMEL, 2004). A criança com deficiência, assim como qualquer criança, precisa experimentar, escutar música, brincar, explorar o ambiente à sua maneira. São essas experiências que farão com que construa uma base para a aprendizagem (BERSCH; MACHADO, 2007).

Rendo e Venga (2006) apostam na possibilidade da educação atravessada pela diversidade e afirmam que se trata de uma transformação e não somente de recursos.

La educacion en y para la diversidad no es una ilusión teórica, sino uma practica necessária que lleva a um processo complejo y dificultoso. Requiere no sólo recursos y médios, sino um cambio em las convecciones culturales, sociales y educativas em toda la sociedad (p. 39-40).

Dessa forma, para que seja possível viabilizar esses preceitos que envolvem a inclusão de criança com deficiências ou transtornos é fundamental que o professor da creche e da préescola tenham suporte em sua formação para que possa promover atitudes democráticas e, assim, enriquecer as experiências por meio de relações e interações atravessadas pela valorização da diversidade (OLIVEIRA, 2013).

\section{Formação de professores}

O educador tem a possibilidade de criar condições para que a criança represente uma noção de si, fortaleça a interação em grupo e a identidade de cada criança, estimule o desempenho de papéis ativos (GAYOTTO, 1992). Esse movimento implica uma educação para a transformação. Gayotto (1992, p.41) afirmou que a transformação não é linear e nem ocorre de fora para dentro.

A educação para a transformação significa um processo aberto, constante e contraditório, da criança consigo mesma, e recíproco, entre ela e as pessoas com quem convive. Educação para a transformação implica em falar de transformação da pessoa, e também da dinâmica das relações das pessoas em um grupo. Pessoas que se comunicam através de relações vinculares, ou seja, que incluem a intra e intersubjetividade que se põem em movimento em alguma ação. Sob esse aspecto a educação é um método ativo [...]

Contudo, ainda há um longo caminho a ser percorrido para que se alcance esse objetivo. Vitta (2010) investigou a concepção dos profissionais do berçário acerca da inclusão de criança com necessidades educacionais especiais na Educação Infantil. O resultado 
mostrou que existem muitas ressalvas, por parte das berçaristas, na inclusão dessas crianças. A justificativa permeou a falta de conhecimento em relação a deficiência e, consequentemente, a noção estereotipada da criança com deficiência. Relataram a insegurança a respeito de como funcionaria esse processo de inclusão. A autora demonstrou preocupação, visto que o discurso das profissionais era de comparação entre a deficiência e a normalidade com relação ao desenvolvimento, sem olhar para a individualidade de cada sujeito. Essa percepção pode fazer com que a escola retenha no berçário a criança com deficiência, acreditando que alcançará determinados níveis de desenvolvimento assim como a criança dita “típica".

Oliveira (2014) pesquisou sobre a concepção de profissionais da Educação Infantil sobre a Educação Especial de crianças de zero a três anos, partindo do princípio que as matrículas de crianças com deficiência têm aumentado, assim como as dúvidas dos profissionais que trabalham com essa população. Foi identificado que parte dos participantes reconhece o direito das crianças com deficiência em frequentar a Educação Infantil, no entanto surgiram receios quanto ao trabalho que devem desempenhar com elas.

Estudos apontam aspectos que interferem na inclusão realizada na Educação Infantil como o espaço físico, recursos materiais e humanos, envolvimento dos gestores e da família, maior financiamento destinado à educação, entretanto acima de tudo, investimento na formação de profissionais (DE VITTA, F.; DE VITTA, A.; MONTEIRO, 2010; MONTE, 2006). Quanto ao espaço físico, os professores sugeriram mudanças arquitetônicas como rampas, corrimão, piso antiderrapante, brinquedos adaptados no parque, assim como o banheiro. No que diz respeito aos recursos materiais citaram com mais ênfase os livros em Braille para crianças cegas e equipamentos para crianças surdas. Outros materiais adaptados, como brinquedos, não foram citados. Aqueles que já existiam, elas desconheciam a maneira de usá-los. Apontaram a necessidade de uma equipe multiprofissional para oferecer apoio e a presença de uma auxiliar com magistério que permaneça em sala (DE VITTA, F.; DE VITTA, A.; MONTEIRO, 2010).

A formação dos professores é abordada por vários autores (DE VITTA, F.; DE VITTA, A.; MONTEIRO, 2010; MONTE, 2006; AMORIN; LIMA; ARAÚJO, 2017) de diferentes maneiras. Alguns estudos apontaram, a partir do discurso das próprias professoras, a necessidade de inserção de temas sobre a Educação Especial na formação inicial do educador, assim como a importância da formação continuada e especializações (VITTA; VITTA; MONTEIRO, 2010; MONTE, 2006). Vitta (2010) concluiu que deve haver 
articulação entre o cuidado e a educação, assim como um olhar para a individualidade e o tempo de desenvolvimento de cada criança, e para os aspectos de ordem biológica e sociocultural.

Ávila, Tochibana e Vaisberg (2008) pesquisaram sobre o imaginário coletivo de professores acerca da inclusão escolar. O resultado apontou angústia despertada nos professores. Eles acreditam que os alunos de inclusão devem ser cuidados pelas mães. Com isso, as autoras afirmaram que além de aspectos técnicos, os professores devem ter suporte emocional ao trabalhar com as crianças incluídas. Já o estudo de Bossi (2017) em que o objetivo era investigar as contribuições do Programa de Acompanhamento para Educadoras de Creche em Contexto Inclusivo na relação entre educadora-bebê com deficiência, as educadoras demonstraram envolvimento com as crianças com deficiência, incluindo-as nas atividades realizadas por todos. De acordo com a autora, as educadoras se mostraram sensíveis às demandas da criança com deficiência e entendiam que exerciam junto delas algo da função materna. Ao mesmo tempo sentiram-se sobrecarregadas em alguns momentos, e no olhar da pesquisadora, a escuta por ela oferecida mostrou-se efetiva, favorecendo a relação educadora com a criança.

Para Diniz e Ferraz (2015), assim como André (2009) e Santos (2008), a formação do professor não é a única razão para uma atuação bem-sucedida ou resultado de melhor rendimento de alunos. As autoras, Diniz e Ferraz, alertaram que a discussão e a reflexão a respeito da formação dos professores não podem ser fechadas, "fazendo com que os programas de formação se construam de maneira a desconsiderar a diversidade profissional e pessoal em que a educação está imersa e provocando a ilusória 'receitualização' do processo ensino-aprendizagem" (DINIZ; FERRAZ, 2015, p. 186).

A formação de um professor nunca estará pronta e acabada a medida que se considera a singularidade de cada criança acompanhada por eles, ou seja, a formação deve acontecer de maneira constante. É fundamental que o professor se questione, sempre, que posição está assumindo diante da inclusão e da diversidade. A formação sem reflexão acerca da própria subjetividade e do que se propõe a enfrentar e transformar, cai em um vazio e, dificilmente dá conta de modificar as construções do imaginário e as representações coletivas sobre o que é diferente de um padrão estabelecido (DINIZ; FERRAZ, 2015).

Patto (2017) abordou a transformação da escola, sobre a escola que temos à escola que queremos. Apontou que para o alcance de uma escola democrática não se deve seguir apenas um caminho "técnico-pedagógico", mas sim acolher e ensinar os alunos considerando-os sujeitos de ação, desejo, crítica e não objetos passivos. Ressalta que um dos princípios para 
uma escola transformadora é preservar o "direito de todas as crianças à escola e à experiência escolar, o acolhimento delas e o respeito às diferenças individuais, quaisquer que elas sejam" (PATTO, 2017, p.88).

Com isso, a formação docente precisa ser constantemente questionada, revisitada para que não se perca de vista a educação com enfoque na diversidade, considerando, na medida do possível, a subjetividade dos professores. Diniz e Ferraz (2015) abordaram essa questão metaforicamente:

Fica a possibilidade de refletir e questionar sobre a formação docente como a linha tênue e frágil que precisa com urgência se constituir de maneira firme e costurar, remendar, ressignificar a educação. Que precisa usar e potencializar cada novelo, tecendo com seus diferentes fios, colorindo com os mais variados aspectos - subjetivos, políticos, cognitivos, sociais, afetivos - esse tapete no qual a diversidade anda mais escondida enquanto possibilidade de inclusão, respeito e mais à mostra como queixa e impossibilidade. Lembrando que a diversidade começa com o olhar atento para as diferenças daqueles (as) que são os dispositivos para a sua consolidação, para aqueles (as) que, antes de professores (as), são sujeitos da diferença, com suas crenças e histórias, com sua vida sexual, com sua cor e gênero (DINIZ; FERRAZ, 2015, p. 191).

Por meio de capacitações, discussões, formação em serviço ou continuada os professores podem ampliar o conhecimento diante de assuntos como a diversidade para expandir as possibilidades de inclusão e, também, a oferta de educação de qualidade a todos.

\section{Considerações finais}

O objetivo desse estudo foi abordar questões acerca da diversidade na Educação Infantil no que diz respeito às crianças com deficiência. Foi detectada uma carência de publicações que aborde a inclusão na Educação Infantil, o que dificulta a problematização da questão. Quanto aos estudos realizados, foram identificadas fragilidades em vários aspectos, de recursos materiais, humanos, apoio da gestão, falta de investimento, mas acima de tudo o que se manteve em destaque foi a formação de professores como aspecto fundamental de uma educação que inclui e respeita a diversidade.

Alguns autores enfatizam a importância da formação continuada aos professores, de investimento em especializações de Educação Especial, já outros apostam que melhores resultados para a conquista de uma escola para todos está associada também a subjetividade do professor e não somente a uma formação no âmbito profissional que não considera a singularidade do professor. 
Além desse olhar para a singularidade do professor na relação com o aluno, da mudança de posicionamento diante da diversidade e da diferença, existem recursos que ajudam no processo de transformação da educação para que a inclusão saia do "papel" e faça parte do cotidiano das escolas de modo efetivo.

Esse modelo de educação intercultural ou educação na e para a diversidade parece ainda estar distante da nossa atual realidade, no entanto, é necessária uma aposta simbólica dos profissionais que atuam com a Educação e Educação Especial para que essa prática possa, pouco a pouco, fazer parte do nosso cotidiano.

\section{REFERÊNCIAS}

ALJUSTREL, Vanessa Isabel Almeida. A relação com a família em contexto de creche e jardim de infância. 2017. 115 f. Dissertação (Mestrado em Educação Pré-escolar) - Instituto Politécnico de Setúbal, Escola Superior de Educação, 2017.

AMORIN, Gabriely Cabestré; LIMA, Elieuza Aparecida de; ARAÚJO, Rita de Cássia Tibério. Formação de professores da educação infantil: reflexões sobre a necessária instrumentalização teórica do profissional atuante com criança com ou sem deficiência. Revista Ibero-Americana de Estudos em Educação, v. 12, n. 1, p. 387-403, 2017.

ANDRÉ, Rita de Cássia Marinho de Oliveira. Creches: desafios e possibilidades. Uma proposta curricular para além do educar e cuidar. 2016. 185 f. Dissertação (Mestrado em Educação) - Pontifícia Universidade Católica de São Paulo, São Paulo, 2016. Disponível em: https://sapientia.pucsp.br/bitstream/handle/18834/2/Rita\%20de\% 20C\%C3\%A1ssia\%20Marinho\%20de\%20Oliveira\%20Andr\%C3\%A9.pdf. Acesso em: 29 jul.2018.

ARAÚJO, Maria Antonieta Nascimento; GAMA, Fernanda Souza; SILVA, Urbiana. Creche de ontem e de hoje: o que os pais esperam dessa instituição? Revista Psicologia, Diversidade e Saúde, Salvador. v. 2, n. 1, p. 3-20, abr. 2013.

ÁVILA, Camila Ferreira de; TOCHIBANA, Miriam; VAISBERG, Tânia Maria José Aiello. Qual é o lugar do aluno com deficiência? O imaginário coletivo de professores sobre a inclusão escolar. Paidéia, v. 18, n. 39, p. 155-164, 2008.

BAHIA, Celi Costa; MOCIUTTI, Solange. A construção da relação creche-família no berçário: contribuição da pesquisa-formação. Revista Ibero-Americana de Estudos em Educação, v. 12, n. 1, p. 371-386, 2017.

BARBOSA, I. G. Prática Pedagógica na Educação Infantil. In: OLIVEIRA, D. A.; DUARTE, A. M. C.; VIEIRA, L. M. F. DICIONÁRIO: trabalho, profissão e condição docente. Belo Horizonte: Faculdade de Educação, 2010. 
BERSCH, R.; MACHADO, R. Conhecendo o aluno com deficiência física. In: SCHIRMER, C. R.; BROWNING, N.; BERSCH, R.; MACHADO, R. Atendimento educacional especializado: Deficiência física. SEESP/SEED/MEC. Brasília, 2007. p. 15-24.

BICHARA, Maria Auxiliadora Alves Cordaro. Considerações sobre a instituição creche e sua relação com a família. In: GAYOTTO, Maria Leonor Cunha et al. (Orgs). Creches: desafios e contradições da criação coletiva da criança pequena. São Paulo: Ícone, 1992. (p. 106-111).

BOSSI, Tatiele Jacques. Inclusão de bebê com deficiência física em creche: programa de acompanhamento para educadoras com base em conceitos winnicottianos. 2017. $82 \mathrm{f}$. Tese (Doutorado em Psicologia) - Universidade Federal do Rio Grande do Sul. Porto Alegre, 2017.

BRASIL. Constituição da República Federativa do Brasil de 1988. Presidência da República. Casa Civil. Subchefia para Assuntos Jurídicos. Brasília, DF, 05 out. 1988. Disponível em: http://www.planalto.gov.br/ccivil_03/constituicao/constituicao.htm. Acesso em: 29 jul.2018

BRASIL. Lei $n^{\circ}$ 9.394, de 20 de dezembro de 1996. Estabelece as diretrizes e bases da educação nacional. Presidência da República. Casa Civil. Subchefia para Assuntos Jurídicos. Brasília, DF, 20 dez. 1996. Disponível em: http://www.planalto.gov.br/ ccivil_03/Leis/L9394.htm. Acesso em: 28 jul. 2018.

BRASIL. Ministério da Educação. Secretaria de Educação Fundamental. Referencial curricular nacional para a educação infantil. Brasília: MEC/SEF, 1998. 3v. Disponível em: http://portal.mec.gov.br. Acesso em: 30 jul. 2018.

BRASIL. Ministério da Educação. Secretaria De Educação Básica. Conselho escolar, gestão democrática da educação e escolha do diretor. vol. 5. Brasília, DF: MEC; SEB, 2004. Disponível em: http://portal.mec.gov.br/seb/arquivos/pdf/Consescol/ce_cad5.pdf. Acesso em: 29 jul. 2018.

BRASIL. Ministério da Educação. Secretaria de Educação Básica. Parâmetros Nacionais de Qualidade para a Educação Infantil. vol. 1. Brasília, DF: MEC; SEB, 2006. Disponível em: http://portal.mec.gov.br/seb/arquivos/pdf/Educinf/eduinfparqualvol1.pdf. Acesso em: 31 jul. 2018.

BRASIL. Ministério da Educação. Secretaria de Educação Básica. Parâmetros Nacionais de Qualidade para a Educação Infantil. vol. 2. Brasília, DF: MEC; SEB, 2006. Disponível em: http://portal.mec.gov.br/seb/arquivos/pdf/Educinf/paraqualvol2.pdf. Acesso em: 28 jul. 2018.

BRASIL. Ministério da Educação. Secretaria de Educação Básica. Diretrizes curriculares nacionais para a educação infantil. Brasília, DF: MEC; SEB, 2010. Disponível em: http://portal.mec.gov.br/index.php?option=com_docman\&view= download\&alias=9769diretrizescurriculares-2012\&category_slug= janeiro-2012-pdf \&Itemid=30192. Acesso em: 28 jul. 2018.

BRASIL. Ministério da Educação. Secretaria de Educação Básica. Base nacional comum curricular: educação é a base. 2018. Disponível em: http://basenacionalcomum.mec.gov.br/wp-content/uploads/2018/02/bncc-20dez-site.pdf. Acesso em: 28 jul. 2018. 
CATALDI, Maria Cristina Cunha. Modificações Sociais e a participação da mulher no mercado de trabalho. In: GAYOTTO, Maria Leonor Cunha et al. (Orgs). Creches: desafios e contradições da criação coletiva da criança pequena. São Paulo: Ícone, 1992. (p. 23-24).

CRESPIN, Graciela. À escuta das crianças na Educação Infantil. São Paulo: Instituto Langage, 2016.

DE VITTA, Fabiana C. F. de; EMMEL, Maria Luisa G. A dualidade cuidado x educação no cotidiano do berçário. Paidéia. Ribeirão Preto, v. 14, n. 28, p. 177-189, 2004.

DIDONET, Vidal. Creche: a que veio...para onde vai... Revista Em aberto, Brasília, DF, v. 18, n. 73, p. 11-27, jun. 2001. Disponível em: http://emaberto.inep.gov.br/ index.php/emaberto/article/view/2133. Acesso em: 30 jul. 2018.

DINIZ, Margareth; FERRAZ, Cláudia Itaborahy. Diferença, diversidade e formação docente: contribuições da psicanálise à discussão da inclusão. Educação (Porto Alegre, impresso), v. 38, n. 2, p. 185-192, maio/ago. 2015.

GAYOTTO, Maria Leonor Cunha. Grupo como espaço de mudança. In: GAYOTTO, Maria Leonor Cunha et al. (Orgs). Creches: desafios e contradições da criação coletiva da criança pequena. São Paulo: Ícone, 1992. (p. 38-43).

JERUSALINSKY, Julieta. Enquanto o futuro não vem: a psicanálise na clínica interdisciplinar com bebês. Salvador, Bahia: Ágalma, 2002.

KRAMER. Sonia. Formação de profissionais de educação infantil: questões e tensões. In: MACHADO, M. L. A. (Org.). Encontros e desencontros em educação infantil. São Paulo: Cortez, 2005.

KUPFER, Maria Cristina et al. Metodologia IRDI nas creches: um acompanhamento do desenvolvimento psíquico na primeira infância. In: KUPFER, Maria Cristina; SZEJER, Myriam (Orgs.). Luzes sobre a clínica e o desenvolvimento de bebês: novas pesquisas, saberes e intervenções. 2. ed. São Paulo: Instituto Langage, 2016. (p. 31-40).

MARANHÃO, Damaris Gomes; SARTI, Cynthia Andersen. Cuidado compartilhado: negociações entre famílias e profissionais em uma creche. Interface - Comunic, Saúde, Educ, v. 11, n. 22, p.257-70, maio/ago. 2007.

MARANHÃO, Damaris Gomes; SARTI, Cynthia Andersen. Creche e família: uma parceira necessária. Cadernos de Pesquisa, v. 38, n. 133, p. 171-194, jan./abr. 2008.

MARIOTTO, Rosa Maria Marini. Atender, cuidar e prevenir: a creche, a educação e a psicanálise. Estilos da Clínica, v. VIII, n. 15, p. 34-47, 2003. Disponível em: http://pepsic.bvsalud.org/pdf/estic/v8n15/v8n15a03.pdf. Acesso em: 30 jul. 2018.

MARIOTTO, Rosa Maria Marini. Cuidar, educar e prevenir: as funções da creche na subjetivação de bebês. São Paulo: Escuta, 2009. 
MONTE, Francisca Roseneide Furtada do. Inclusão na educação infantil: concepções e perspectivas de educadoras de creche. 2006. 119 f. Dissertação de Mestrado - Universidade Católica de Brasília, Brasília, 2006.

NONO, Maévi Anabel. Educar e cuidar nas creches e pré-escolas. UNIVESP, Universidade Estadual Paulista "Júlio de Mesquita Filho", 2015. Disponível em: http://www.acervodigital.unesp.br/bitstream/123456789/230/1/01d12t04.pdf. Acesso em: 30 jul. 2018.

OLIVEIRA, A. A. S. O processo de inclusão no Brasil: políticas públicas para o educando com necessidades educacionais especiais. In: GENARO, K. F.; LAMÔNICA, D. A. C.; BEVILACQUA, M. C. O processo de comunicação: contribuição para a formação de professores na inclusão de indivíduos com necessidades educacionais especiais. São José dos Campos, SP: Pulso Editora, 2006, p. 255-276.

OLIVEIRA, Cinthya Campos de. Concepções de profissionais da Educação Infantil sobre a Educação Especial para crianças de zero a três anos. 2014.186 f. Dissertação de Mestrado - Universidade Federal do Espirito Santo, Vitória, 2014.

OLIVEIRA, Zilma de Moraes de et al. Creches: crianças, faz de conta e cia. 16 ed. Petrópolis, Rio de Janeiro: Vozes, 2011.

OLIVEIRA, Zilma De Moraes Ramos de. Educação Infantil: fundamentos e métodos. São Paulo: Cortez, 2013.

PATTO, Maria Helena Souza. A escola transformadora: da escola que temos à escola que queremos. In: KUPFER, Maria Cristina Machado; PATTO, Maria Helena Souza; VOLTOLINI, Rinaldo. (Orgs.). Práticas Inclusivas em escolas transformadoras: acolhendo o aluno sujeito. São Paulo: Escuta: Fapesp, 2017. (p.67-89).

PEREIRA, Paulo Celso; MATSUKURA, Thelma Simões. Inclusão escolar e educação infantil: um estudo de caso. Revista Educação Especial, Santa Maria, v. 26, n. 45, p. 125144, jan./abr. 2013.

RENDO, Alicia Devalle de; VEGA, Viviana. Una escuela en y para la diversidad: el entramado de la diversidad. Buenos Aires: Aique, 2006.

SANTOS, Lucíola Licínio de Castro Paixão. Formação docente: políticas e processos. In: Seminário redestrado: nuevas regulaciones en América Latina, 7, 2008, Buenos Aires. Anais eletrônicos... Buenos Aires: Redestrado, 2008. Disponível em:

http://www.fae.ufmg.br/estrado/cdrom_seminario_2008/ textos/ponencias/Ponencia\%20Luc\%C3\%ADola\%20 Licinio\%20Santos.pdf. Acesso em: 30 jul. 2018.

SILVA, Cristiane Ribeiro da; BOLSANELLO, Maria Augusta. No Cotidiano das creches o cuidar e o educar caminham juntos. Interação em Psicologia, v. 6, n. 1, p. 31-36, 2002. Disponível em: http://revistas.ufpr.br/psicologia/article/view/3190. Acesso em: 30 jul. 2018.

VITTA, Fabiana Cristina Frigieri de. A inclusão de crianças com necessidades especiais na visão de berçaristas. Cadernos de Pesquisa, v.40, n.139, p.75-93, jan./abr. 2010. 
VITTA, Fabiana Cristina Frigieri de; VITTA, Alberto de; MONTEIRO, Alexandra S. R. Percepção de professores de educação infantil sobre a inclusão da criança com deficiência.

Rev. Bras. Ed. Esp., Marília, v. 16, n. 3, p. 415-428, set./dez. 2010.

\section{Como referenciar este artigo}

ADURENS, F. D. L.; PROSCENCIO, P. A.; WELLICHAN, D. S. P. Reflexões sobre a diversidade na educação infantil: um olhar para a formação de professores. Doxa: Rev. Bras. Psico. e Educ., Araraquara, v. 20, n. 2, p. 150-163, jul./dez., 2018. e-ISSN: 2594-8385. DOI: 10.30715/doxa.v20i2.11638

Submetido em: 04/08/2018

Aprovado em: 12/09/2018 